\title{
Nhận diện tranh chấp giữa các thành viên, giữa thành viên với công ty theo pháp luật Việt Nam hiện nay
}

\author{
Trần Trí Trung* \\ Khoa Luật, Đại học Quốc gia Hà Nội, 144 Xuân Thủy, Cầu Gián, Hà Nội, Việt Nam \\ Nhận ngày 11 tháng 10 năm 2017 \\ Chỉnh sửa ngày 22 tháng 11 năm 2017; Chấp nhận đăng ngày 28 tháng 12 năm 2017
}

\begin{abstract}
Tóm tắt: Nội dung bài viết làm rõ những vấn đề về nguyên nhân hình thành, bản chất, đặc điểm pháp lý và các loại hình tranh chấp giữa các thành viên, giữa thành viên với công ty nhằm bổ sung và góp phần hoàn thiện cơ sở lý luận cho việc nhận diện tranh chấp giữa các thành viên, giữa thành viên với công ty. Nội dung bài viết cũng đồng thời làm rõ tính chất đặc thù của một loại hình tranh chấp trong lĩnh vực kinh doanh thương mại, xuất hiện và tồn tại gắn liền với quá trình thành lập và tổ chức hoạt động của công ty.
\end{abstract}

Tù khóa: Tranh chấp, công ty, thành viên công ty.

\section{1. Đặt vấn đề}

Quan hệ giữa người với người trong xã hội tự nó luôn bao hàm, tiềm ẩn những bất đồng, mâu thuẫn, xung đột. Bởi thế, tranh chấp là hiện tượng phổ biến, có tính tất yếu khách quan. Trong qua trình cùng nhau tạo lập và vận hành một thực thể kinh doanh, việc tồn tại những bất đồng, xung đột giữa các thành viên ty cũng không là ngoại lệ. Nền kinh tế thị trường với những sự tác động khắc nghiệt của các quy luật giá trị, quy luật cạnh tranh cùng với sự khác biệt về văn hóa, trình độ hiểu biết giữa các chủ thể càng khiến cho những xung đột, mâu thuẫn trở nên đa dạng với tính chất ngày càng phức tạp, ảnh hưởng trực tiếp đến quyền và lợi ích của thành viên công ty và công ty, ảnh hưởng đến sự ổn định, phát triển kinh tế xã hội. Làm rõ những vấn đề pháp lý về tranh chấp giữa các

\footnotetext{
*ĐT.: 84-983338383.

Email: trungtt@vnu.edu.vn

https://doi.org/10.25073/2588-1167/vnuls.4132
}

thành viên, giữa thành viên với công ty là vấn để có ý nghĩa lý luận và thực tiễn làm cơ sở cho việc thống nhất nhận thức trong việc nhận diện và triển khai các biện pháp phòng ngừa, giải quyết tranh chấp giữa các thành viên, giữa thành viên với công ty.

\section{Nguyên nhân hình thành, phát sinh tranh chấp giữa các thành viên, giữa thành viên với công ty}

Trong hệ thống pháp luật Việt Nam, tranh chấp giữa các thành viên công ty, giữa thành viên với công ty đã được đề cập từ luật công ty năm 1990. Trong các văn bản pháp luật về tố tụng dân sự, kinh tế cùng thời gian này, tranh chấp giữa các thành viên công ty, giữa thành viên với công ty được xác định là một loại việc thuộc thẩm quyền giải quyết của tòa án [1]. Bộ luật Tố tụng Dân sự năm 2004, năm 2015 và các văn bản hướng dẫn thi hành cũng có quy định tương tự, đồng thời xác định các tranh 
chấp giữa công ty với các thành viên của công ty, giữa các thành viên của công ty với nhau liên quan đến việc thành lập, hoạt động, giải thể, sáp nhập, hợp nhất, chia, tách, chuyển đổi hình thức tố chức của công ty là những tranh chấp thuộc lĩnh vực kinh doanh thương mại thộc thẩm quyền giải quyết sơ thẩm của tòa án nhân dân cấp tỉnh [2].

Mặc dù được xác định từ rất sớm và nhiều lần được nhắc lại trong hệ thống pháp luật về kinh doanh thương mại, nhưng cho đến nay trong hệ thống pháp luật nước ta vẫn chưa có một khái niệm đủ để khái quát về tranh chấp giữa các thành viên công ty, giữa thành viên với công ty. Trong một nỗ lực thực tế nhằm giải quyết những khó khăn, vướng mắc từ thực tiễn giải quyết các vụ việc liên quan, năm 2005, Hội đồng thẩm phán Tòa án nhân dân tối cao trên cơ sở thống nhất với Viện trưởng Viện Kiểm sát nhân dân tối cao và Bộ trưởng Bộ Tư pháp đã thống nhất nội dung hướng dẫn để nhận diện và phân biệt tranh chấp giữa các thành viên, giữa thành viên với công ty. Đến năm 2012, nội dung này được nhắc lại trong Nghị quyết số 03/2012/NQ-HĐTP. Tuy nhiên, nội dung được đề cập chỉ là hướng dẫn phân biệt tranh chấp trên cơ sở liệt kê một số tiêu chí về chủ thể và lĩnh vực tranh chấp, vì thế không thể bao quát được các trường hợp tranh chấp giữa các thành viên công ty, giữa thành viên với công ty trong thực tiễn [3].

Vấn đề xác định nguyên nhân xảy ra tranh chấp có ý nghĩa quan trọng, là cơ sở để xác định các biện pháp điều chỉnh nhằm giải quyết tranh chấp, đồng thời tạo điều kiện để áp dụng các phương thức phòng ngừa, hạn chế tranh chấp.

Một trong những đặc điểm của những công ty được tạo nên từ vốn góp của nhiều thành viên là sự tách bạch về sở hữu tài sản giữa chủ sở hữu công ty với công ty. Có nghĩa là, thành viên công ty thực chất là người giữ quyền sở hữu đối với tài sản của công ty nhưng lại không trực tiếp sử dụng tài sản của công ty với tư cách chủ sở hữu mà thông qua cơ chể ủy quyền cho công ty toàn quyền sử dụng tài sản với tư cách của chủ sở hữu. Trong khi đó, với tư cách một pháp nhân độc lập, công ty luôn được tổ chức và vận hành dưới sự điều hành và quản trị của một bộ máy đại diện nhân danh công ty. Cơ chế đại diện với khả năng diễn ra sai lệch trong quá trình thực hiện nhiệm vụ và quyền hạn luôn tiềm ẩn nguy cơ xâm hại đến quyền và lợi ích chính đáng của người ủy quyền. Mặt khác, trong công ty đối vốn, thường có số lượng thành viên lớn, thậm chí là không giới hạn, khả năng phân hóa trong tổ chức dẫn đến những sai lệch trong việc thực hiện các thỏa thuận trong quan hệ ủy quyền và xâm hại đến các quyền và nghĩa vụ của thành viên là $x u$ hướng tất yếu.

Về cơ sở lý luận, nguyên nhân phát sinh tranh chấp được xác định trên hai phương diện, nguyên nhân chủ quan và nguyên nhân khách quan. Trên cơ sở kết quả khảo sát một số vụ việc tranh chấp trong thời gian 10 năm trở lại đây, chúng tôi nhận thấy tranh chấp giữa các thành viên, giữa thành viên với công ty có các nguyên nhân cơ bản sau:

Nguyên nhân khách quan: Là những yếu tố tồn tại bên ngoài quan hệ giữa các thành viên, giữa thành viên với công ty. Mâu thuẫn, bất đồng trong quan hệ giữa thành viên với thành viên, giữa thành viên với công ty có thể hình thành và phát sinh do những yếu tố bên ngoài, không phụ thuộc vào ý chí chủ quan của các bên. Đó có thể là những yếu tố như pháp luật, văn hóa, tác động của những quy luật về giá trị, cạnh tranh trong thị trường, sự mơ hồ, lỏng lẻo của các mối quan hệ đã được xác lập giữa các thành viên, giữa thành viên với công ty. Trong số đó, sự khuyết thiếu và không hoàn chỉnh, bất cập của các quy định pháp luật về cơ chế xác lập, thực hiện và bảo vệ quyền, nghĩa vụ của các thành viên và của công ty được xem là nguyên nhân khách quan quan trọng hàng đầu dẫn đến sự hình thành và phát triển của các tranh chấp giữa các thành viên, giữa thành viên với công ty.

Nguyên nhân chủ quan: Là những yếu tố xuất phát từ bên trong, thể hiện ý chí của thành viên nói riêng và các các bền tranh chấp nói chung. Đây được xem là nguyên nhân căn bản và chủ yếu yếu dẫn đến các tranh chấp giữa thành viên với thành viên, giữa thành viên với 
công ty. Trong từng mối quan hệ cụ thể, bất đồng, mâu thuẫn phát sinh khi chủ thể có nhận thức về sự không phù hợp của việc thực hiện các quyền và nghĩa vụ mà nguyên nhân chính là xuất phát từ hành vi sai lệch của bên có nghĩa vụ tương ứng với quyền hoặc lợi ích của bên còn lại. Kể cả trong trường hợp bên có nghĩa vụ đã không thực hiện hoặc thực hiện không đúng các quyền và nghĩa vụ của mình, việc có phát sinh tranh chấp hay không cũng vẫn phụ thuộc vào ý chí chủ quan của bên có quyền yều cầu. Ngoại trừ những trường hợp vi phạm pháp luật, xâm hại trật tự công cộng và đạo đức xã hội, dựa trên nguyên tắc về quyền tự định đoạt của các chủ thể trong kinh doanh thương mại, tranh chấp chỉ phát sinh khi bên có quyền hoặc có lợi ích liên quan có những hành động chống lại những biểu hiện sai lệch đã xảy ra. Trên cơ sở khảo sát một số vụ việc tranh chấp giữa các thành viên, giữa thành viên với công ty trong vòng 10 năm trở lại đây, theo chúng tôi, nguyên nhân chủ quan và có tính phổ biến dẫn đến tranh chấp tranh chấp giữa các thành viên, giữa thành viên với công ty gồm:

Người quản lý công ty điều hành công ty không vì lợi ích của chủ sở hữu là các thành viên công ty; Các thành viên đa số vốn thỏa thuận nhằm tước đoạt quyền lợi của thành viên thiểu số trong công ty; Các thành viên nắm quyền kiểm soát công ty tước đoạt quyền lợi của thành viên không nắm quyền kiểm soát công ty; Thành viên điều hành quản lý công ty tiến hành những giao dịch vụ lợi ảnh hưởng đến quyền lợi của các cổ đông; Công ty không thực hiện hoặc thực hiện không đúng các nghĩa vụ về phân phối lợi nhuận đối với thành viên; Công ty không đảm bảo thực hiện các quyền của thành viên; Công ty không cung cấp hoặc cung cấp thông tin không đầy đủ về hoạt động của công ty; thành viên công ty hoặc người quản lý điều hành công ty không có điều kiện tìm hiểu thông tin, thiếu hiểu biết về các quyền và nghĩa vụ, hành động thiếu thiện chí, cẩu thả; Quản lý (quản trị) công ty lỏng lẻo, thiếu chuyên nghiệp; Các quy định (thỏa thuận) trong nội bộ công ty không đầy đủ, thiếu rõ ràng, không cụ thể; cơ chế giám sát và thực thi pháp luật chưa hiệu quả; v.v...

Tựu trung lại, trên cả phương diện chủ quan và khách quan, tranh chấp giữa các thành viên, giữa thành viên với công ty phát sinh theo ba nhóm nguyên nhân cơ bản sau: Tranh chấp phát sinh do thành viên công ty hoặc công ty không thực hiện hoặc thực hiện không đúng các quyền và nghĩa vụ đã được xác lập; do cơ chế quản lý, kiểm tra giám sát (cả trong nội bộ công ty và của luật pháp) không chặt chẽ, lỏng lẻo, kém hiệu quả; do hệ thống pháp luật và các thỏa thuận nội bộ còn chưa đầy đủ, không rõ ràng, cụ thể.

Có thể nhận thấy, tranh chấp giữa các thành viên, giữa thành viên với công ty có thể phát sinh bởi nhiều nguyên nhân khác nhau. Nguyên nhân sâu xa mang tính chủ quan của tranh chấp giữa các thành viên, giữa thành viên với công ty là do hành vi tư lợi, không trung thực, thiếu thiện chí, làm sai lệch bản chất, xâm phạm đến các quan hệ, các thỏa thuận đã được xác lập giữa các thành viên, giữa thành viên với công ty.

\section{3. Đặc điểm pháp lý của tranh chấp giữa các thành viên, giữa thành viên với công ty}

Được xác định là chủ sở hữu, thành viên công ty là chủ thể quan trọng có vai trò quyết định sự hình thành, tồn tại và hoạt động của công ty. Các quyền và nghĩa vụ của thành viên được xác định xuất phát từ các quyền của chủ sở hữu, hình thành và tồn tại gắn liền với quá trình thành lập và duy trì hoạt động của công ty.

Tranh chấp giữa các thành viên công ty với nhau thực chất là những bất đồng, mâu thuẫn trong việc thực hiện những thỏa thuận giữa các thành viên về các nội dung liên quan đến xác lập quyền sở hữu, đến các lợi ích vật chất có thể có được của thành viên với tư cách đồng chủ sở hữu, về ứng xử của thành viên liên quan đến tổ chức và hoạt động của công ty.

Tranh chấp giữa thành viên với công ty có tính chất của tranh chấp giữa chủ sở hữu và đối tượng sở hữu. Thành viên, với tư cách là chủ sở hữu công ty được bắt nguồn từ quyền sở sở hữu 
phần vốn góp và tài sản trong công ty. Trong khi đó, công ty là một loại chủ thể đặc biệt, có các quyền và nghĩa vụ độc lập với chủ sở hữu công ty nhưng đồng thời cũng là đối tượng sở hữu trong mối quan hệ với những thành viên là chủ sở hữu công ty. Giữa các thành viên và công ty luôn tồn tại các mối liên hệ được ghi nhận thông qua các quyền và nghĩa vụ đã được xác lập theo thỏa thuận giữa các thành viên hoặc theo các quy định của pháp luật. Với mối quan hệ phụ thuộc và gắn bó đã được xác lập, tranh chấp giữa các thành viên, giữa thành viên với công ty luôn tác động trực tiếp đến tổ chức và sự tồn tại của công ty.

Tranh chấp giữa thành viên với công ty xảy ra khi có sự bất đồng, mâu thuẫn liên quan đến việc thực hiện các quyền và nghĩa vụ được xác lập giữa các thành viên, hoặc giữa các thành viên với công ty.

Về bản chất, tranh chấp giữa các thành viên công ty, giữa thành viên với công ty suy cho cùng là những bất đồng, mâu thuẫn về các lợi ích kinh tế, quyền quản lý công ty gắn liền với các quyền và nghĩa vụ của công ty và các nhà đầu tư là chủ sở hữu công ty trong hoạt động kinh doanh thương mại.

Một cách khái quát, tranh chấp giữa các thành viên, giữa thành viên với công ty là những bất đồng mâu thuẫn, xung đột về quyền và nghĩa vụ giữa các thành viên công ty, giữa thành viên với công ty trong quá trình tồ chức và hoạt động của công ty.

Trên cơ sở khái niệm đã nêu, tranh chấp giữa các thành viên, giữa thành viên với công ty, có những đặc điểm pháp lý cơ bản sau:

Về chủ thể: Chủ thể trong mối quan hệ tranh chấp giữa các thành viên công ty là các cá nhân, tổ chức có quyền sở hữu phần vốn góp trong công ty. Trong hầu hết các loại tranh châp giữa các thành viên, cả hai bên chủ thể tranh chấp đều là thành viên trong cùng một công ty. Có một ngoại lệ, trường hợp liên quan đến tranh chấp về chuyển nhượng vốn góp với thành viên của công ty, một bên chủ thể có tranh chấp có thể là người không phải là thành viên công ty [3].
Trong quan hệ tranh chấp giữa thành viên với công ty, một bên chủ thể là công ty, bên còn lại là thành viên công ty với tư cách là người có phần quyền sở hữu trong công ty. Nói cách khác, trong quan hệ tranh chấp này, thành viên tranh chấp với chính công ty mà thành viên đó có vai trò là chủ sở hữu. Công ty có tư cách pháp lý độc lập, trở thành một bên trong quan hệ tranh chấp với một bên chủ thể là đồng chủ sở hữu công ty.

Về nội dung: Tranh chấp giữa các thành viên, giữa thành viên với công ty có nội dung phản ánh những giá trị vật chất hoặc phi vật chất được xác định bởi các quyền và nghĩa vụ của công ty, quyền và nghĩa vụ của thành viên trong công ty. Nội dung tranh chấp giữa các thành viên, giữa thành viên với công ty rất đa dạng và phong phú, có quan hệ tương ứng, gắn liền với các quyền và nghĩa vụ đã hoặc có thể được xác lập của các bên (thông qua thỏa thuận của các thành viên công ty hoặc theo quy định của pháp luật).

Về bản chất: Tranh chấp giữa các thành viên, giữa thành viên với công ty là những bất đồng, mâu thuẫn giữa các bên trong việc thực hiện các quyền và nghĩa vụ của công ty và các thành viên.

Đối tượng và phạm vi phát sinh tranh chấp: Về phạm vi, tranh chấp giữa các thành viên, giữa thành viên với công ty phát sinh trong quá trình thực hiện hoạt động kinh doanh thương mại của chủ thể. Tranh chấp phát sinh luôn gắn liền với những những quan hệ đã được xác lập trong nội bộ công ty, đối tượng của tranh chấp vì thế cũng rất đa dạng, hình thành trong quá trình thành lập, hoạt động của công ty, tổ chức và tổ chức lại công ty.

Là một dạng tranh chấp phát sinh trong quá trình thực hiện hành vi kinh doanh của các chủ thể, với các đặc điểm nêu trên, so với các tranh chấp kinh doanh thương mại khác, tranh chấp giữa các thành viên công ty, giữa thành viên với công ty có các điểm khác biệt cơ bản như:

Khác biệt về chủ thể: Các bên trong mối quan hệ tranh chấp giữa các thành viên công ty, giữa thành viên với công ty đều là những người 
(cá nhân, tổ chức) có chung lợi ích trong cùng một công ty. Trong mối quan hệ tổ chức, thành viên công ty là bộ phận cấu thành của một chủ thể kinh doanh, các bền tranh chấp luôn có mối quan hệ gắn bó trách nhiệm và quyền lợi trong một chủ thể chung, với tư cách là đồng chủ sở hữu. Đây cũng là dấu hiệu dẫn đến quan niệm tranh chấp giữa các thành viên công ty, giữa thành viên với công ty là loại hình tranh chấp trong nội bộ. Trong khi đó, các tranh chấp kinh doanh thương mại khác thường phát sinh giữa các chủ thể kinh doanh có tư cách độc lập, có các quyền là lợi ích đối xứng nhau, phát sinh giữa một bên là công ty với một bên chủ thể khác không có mối quan hệ phụ thuộc và gắn bó trong cùng một tổ chức.

Khác biệt về bản chất và nội dung tranh chấp: Tranh chấp giữa các thành viên, giữa thành viên với công ty là sự phản ánh những bất đồng, mâu thuẫn trong việc thực hiện quyền và nghĩa vụ trong nội bộ công ty liên quan đến tổ chức, hoạt động và tổ chức lại công ty. Nội dung tranh chấp phản ánh và có mối liên hệ trực tiếp đến các quyền, nghĩa vụ của các bên gắn liền với quyền sở hữu công ty của các bên hoặc một bên trong tranh chấp. Còn tranh chấp trong kinh doanh thương mại khác là những bất đồng, mâu thuẫn về các quyền và nghĩa vụ liên quan đến lợi ích vật chất được xác lập thông qua những giao dịch cụ thể trong việc thực hiện các hành vi thương mại, thể hiện trong việc một bên trong quan hệ thương mại đã không thực hiện hoặc thực hiện không đúng hợp đồng đã giao kết. Giữa các bên không tồn tại mối quan hệ trực tiếp và gắn bó hữu cơ về tổ chức và sở hữu công ty.

Khác biệt về căn cứ và phạm vi phát sinh tranh chấp: Tranh chấp giữa các thành viên, giữa thành viên với công ty phát sinh luôn gắn liền với những những quan hệ ổn định, mang tính tổ chức được xác lập trong nội bộ công ty, còn tranh chấp kinh doanh thương mại khác thường phát sinh trong quá trình các chủ thể kinh doanh tiến hành giao kết và thực hiện các hành vi thương mại cụ thể.

So với tranh chấp trong giao lưu dân thông thường, tranh chấp giữa các thành viên, giữa thành viên công ty có những điểm khác biệt như: Tranh chấp giữa các thành viên, giữa thành viên với công ty hình thành và phát sinh trong quá trình các chủ thể tham gia thiết lập tổ chức và thực hiện tổ chức hoạt động kinh doanh. Đối tượng tranh chấp giữa các thành viên, giữa thành viên với công ty là các quyền và nghĩa vụ có mối liên hệ gắn bó chặt chẽ với chủ thể kinh doanh, phản ánh hoạt động kinh doanh, phản ánh bất đồng, mâu thuẫn nội tại trong quá trình tổ chức hoạt động kinh doanh thương mại của các chủ thể. Trong quan hệ tranh chấp giữa các thành viên, giữa thành viên với công ty, chủ thể là các cá nhân, tổ chức đã tham gia đầu tư, kinh doanh và có mối quan hệ gắn bó, phụ thuộc lẫn nhau trong cùng một tổ chức kinh doanh. Nội dung tranh chấp giữa các thành viên, giữa thành viên với công ty gắn liền với quyền và nghĩa vụ hình thành trong quá trình tổ chức và hoạt động kinh doanh của công ty với tư cách là một chủ thể kinh doanh. Khách thể tranh chấp giữa các thành viên, giữa thành viên với công ty là các giá trị vật chất hoặc các lợi ích phi vật chất gắn liền với tổ chức và hoạt động của công ty.

\section{Phân loại tranh chấp giữa các thành viên, giữa thành viên với công ty}

Phân loại tranh chấp là việc lựa chọn và xác định tranh chấp thành những nhóm nhất định phục vụ cho công việc nghiên cứu và định hướng biện pháp giải quyết tranh chấp phù hợp với tính chất, nội dung tranh chấp. Với cách tiếp cận đó, việc phân loại tranh chấp giữa các thành viên, giữa thành viên với công ty thực hiện theo những nguyên tắc sau:

Nguyên tắc đảm bảo tính hệ thống và toàn diện: Tranh chấp giữa các thành viên, giữa thành viên với công ty có nội dung phong phú và đa dạng, có thể phát sinh ở bất kỳ giai đoạn nào trong suốt quá trình tồn tại và hoạt động của công ty. Việc phân loại tranh chấp đòi hỏi phải phản ánh đầy đủ các loại hình tranh chấp, việc chia thành các nhóm loại tranh chấp phải đảm bảo được tính tổng thể tranh chấp trên tất 
cả các lĩnh vực, tương ứng với các quyền và nghĩa vụ đã được xác định.

Nguyên tắc tôn trọng và phản ánh đúng bản chất quan hệ bị tranh chấp: Đòi hỏi việc phân loại phải bám sát các nhóm quyền và nghĩa vụ làm phát sinh tranh chấp.

Nguyên tắc tách biệt giữa tranh chấp liên quan trực tiếp đến lợi ích vật chất và tranh chấp về những giá trị phi vật chất: Tương ứng với các nhóm quan hệ phát sinh tranh chấp, suy cho cùng chúng đều phản ánh lợi ích kinh tế. Thực hiện tách biệt giữa tranh chấp liên quan trực tiếp đến lợi ích vật chất và tranh chấp về những giá trị phi vật chất khi phân loại và kết hợp phân loại theo chủ thể tranh chấp giữa các thành viên và tranh chấp giữa thành viên với công ty nhằm đảm bảo cho việc phân loại tranh chấp có thể chỉ ra được quy mô và tính chất phức tạp của các loại tranh chấp.

Nguyên tắc xác định tiêu chí phân loại trên cơ sở tính chất, đặc điểm của tranh chấp: Xác định tiêu chí phân loại căn cứ vào tính chất, đặc điểm của tranh chấp nhằm đảm bảo cho các nhóm tranh chấp được phân loại thỏa mãn tính tương đồng về loại hình chủ thể, đối tượng và nội dung tranh chấp.

Trên cơ sở các nguyên tắc nêu trên, có thể xác định các loại hình tranh chấp chủ yếu giữa các thành viên, giữa thành viên với công ty dựa trên các căn cứ cụ thể về chủ thể, các quyền và nghĩa vụ của chủ thể.

Căn cứ theo chủ thể tranh chấp: Theo tiêu chí này, tranh chấp giữa các thành viên, giữa thành viên với công ty bao gồm ba loại hình. Gồm: Tranh chấp có các bên chủ thể là các thành viên trong cùng một công ty; Tranh chấp giữa một bên chủ thể là thành viên công ty với một bên chủ thể là người không phải là thành viên công ty liên quan đến việc chuyển nhượng phần vốn góp của thành viên trong công ty; và tranh chấp giữa một bên là công ty với một bên là thành viên công ty.

Căn cứ theo các nhóm quyền và nghĩa vụ của công ty và thành viên công ty: Theo tiêu chí này, tranh chấp giữa các thành viên, giữa thành viên với công ty bao gồm ba nhóm (Tranh chấp về quyền sở hữu đối với phần vốn góp; Tranh chấp về tài sản, lợi ích vật chất; Tranh chấp về tổ chức, tổ chức lại và quản lý công ty) với mười một loại tranh chấp điển hình. Gồm: Tranh chấp về phần vốn góp, trình tự thủ tục góp vốn, quyền góp vốn; Tranh chấp về giá trị của phần vốn góp; Tranh chấp về điều kiện thủ tục xác lập, chấm dứt tư cách thành viên; Tranh chấp về chuyển nhượng, tặng cho, thừa kế phần vốn góp; Tranh chấp về phân chia lợi nhuận thu được, về mức độ chịu lô̂ tương ứng của thành viên trong quá trình tồn tại và phát triển của công ty; tranh chấp về giá trị tài sản còn lại khi công ty chấm dứt hoạt động; Tranh chấp về xây dựng và thực hiện các quy tắc xử sự nội bộ công ty; Tranh chấp về việc thực hiện nội dung thỏa thuận giữa các thành viên về tổ chức và hoạt động của công ty, về thực hiện quyền và nghĩa vụ của thành viên công ty; Tranh chấp về quyền dự họp, tham gia thảo luận, bầu cử, biểu quyết, thông qua quyết định những vấn đề liên quan đến tồ chức, tổ chức lại và các hoạt động khác của công ty; Tranh chấp về quyền trao đồi và tiếp nhận thông tin giữa các thành viên, giữa thành viên với công ty trong nội bộ công ty; Tranh chấp trong việc thực hiện kiểm tra, giám sát tình hình hoạt động của công ty và của các thành viên quản lý công ty.

\section{Kết luận}

Sức hấp dẫn về lợi ích kinh tế là động lực thúc đẩy nhà đầu tư bỏ vốn kinh doanh. Mặt khác, trong nhiều trường hợp, chính lợi ích kinh tế đã khiến cho các chủ thể sẵn sàng thực hiện những hành vi sai trái để nhằm đạt được những lợi ích kinh tế vượt quá mức độ chính đáng mà họ được hưởng. Bao giờ cũng vậy, khả năng về bất bình đẳng, không công bằng, xung đột về lợi ích kinh tế luôn tiềm ẩn và là căn nguyên làm phát sinh tranh chấp giữa những chủ đầu tư trong cùng một công ty.

Trên con đường hướng tới những giá trị về công bằng, pháp luật luôn là công cụ hữu hiệu để giúp những nhà đầu tư tìm ra phương thức tự bảo vệ quyền lợi. Để tiến tới mục tiêu đó, đòi 
hỏi cần phải có một hệ thống pháp luật hoàn chỉnh và đồng bộ, phản ánh được đầy đủ các quyền và nghĩa vụ của chủ đầu tư cũng như cơ chế hiệu quả để thực hiện các quyền đó cùng với nguồn lực đảm bảo vận hành hệ thống. Hiểu rõ bản chất, đặc điểm và các loại hình tranh chấp giữa các thành viên, giữa thành với công ty là cơ sở để tiến tới hoàn thiện các quy định pháp luật nhằm bảo vệ tốt nhất quyền lợi của thành viên công ty và công ty, góp phần ổn định môi trường đầu tư kinh doanh, phát triển kinh tế xã hội của đất nước.

\section{Tài liệu tham khảo}

[1] Ủy Ban Thường vụ Quốc hội nước CHXHCN Việt Nam (1994) Pháp lệnh thủ tục giải quyết các vụ án kinh tế, NXB Chính trị Quốc gia, Hà Nội).

[2] Quốc Hội nước Cộng hòa Xã hội chủ nghĩa Việt Nam (2004), Bộ Luật Tố tụng Dân sự số 24/2004/QH11, NXB Chính trị Quốc gia, Hà Nội.

[3] Toà án nhân dân tối cao (2012), Nghị quyết số 03/2012/NQ-HĐTP hướng dẫn thi hành phần thứ nhất "Những quy định chung" của Bộ luật Tố tụng dân sự đã được sửa đổi, bổ sung theo Luật sửa đổi, bổ sung một số điều của Bộ luật tố tụng dân sự, Hà Nội.

\title{
Identifying Disputes between a Company and Its Members and among Members under the Current Vietnamese Laws
}

\author{
Tran Tri Trung \\ VNU School of Law, 144 Xuan Thuy, Cau Giay, Hanoi, Vietnam
}

\begin{abstract}
This article clarifies the issues relating to the causes of formation, the nature, characteristics and types of legal disputes between a company and its members and among members. This clarification aims at complementing and contributing to the improvement of theoretical basis for identifying such legal disputes. This article also clarifies the specific characteristics of a type of legal dispute in the commercial business sector in connection with the establishment and implementation of a company's operations.
\end{abstract}

Keywords: Disputes, company, company's membership 